\title{
Nutritional status assessment of under five years' children of Magar Community of Nisdi Rural Municipality, Palpa
}

\author{
Pushkar Singh Raikhola PhD \\ Monitoring Directorate, Tribhuwan University, Kirtipur, Kathmandu, Nepal \\ Email: pushkar_raikhola@yahoo.com \\ Tara Gaire, (MscN) \\ Department of Nursing, Innovative college of health Science, Kathmandu, Nepal \\ Email: taragaire33@gmail.com
}

\section{Krishna Prasad Pathak,(PhD, CDP)}

Nepal Open University, Nepal. Alzheimer Related Dementia Society Nepal.

Email: krishnapathak32@gmail.com

Received: November 09, 2020; Revised \& Accepted: December 11, 2020; Published: February18, 2021

(C) Copyright: Nepali (2021).

\begin{abstract}
Malnutrition is one of the most important public health problems of developing countries where resources are very limited. The common cause of malnutrition is lack of access to the nutritious food, poor breastfeeding practices, offering the wrong foods, and not ensuring that the child gets enough nutritious food. The prevailing high rate of child under-nutrition in the country is one of the major contributing factors of under-five mortality.

We aimed to find out nutritional status of children under five years in Magar community group who are financially poor.

This was applied cross-sectional study in 115 children (under 5 years) of Magar ethnic group of Nisdi Rural Municipality, Palpa to assess situation of the nutrition. Statistical analysis was performed using SPSS 20.0 version for the anlysis the results.

This study revealed that $96.5 \%$ children were fed with colostrum and $60.2 \%$ of the children out of 108 children aged 6-59 months were exclusively breastfed for 6 months. Likewise, 56.5\% children received timely initiation of complementary feeding. Out of 115 children, $60 \%$ were still continuing breastfeeding whereas 1.7\% dropped in less than 2 year and 38.3\% continued for more than 2 years. Based on Gomez-classification for weight for age (Underweight), among 115 children only $26.1 \%$ children aged under 59 months were normal. While, more than half (53.9\%) were mildly malnourished, 16.5\% were moderately malnourished and 3.5\% were severely malnourished. Based on Waterlow's classification for Weight for height (wasting), less than half
\end{abstract}


(46.1\%) children aged under 59 months were normal. While, 40.9\% were mildly malnourished, $10.4 \%$ were moderately malnourished and $2.6 \%$ were severely malnourished. Similarly, based on Waterlow's classification for Height for age (Stunting), 52.2\% children aged under 59 months were normal. While, 23.5\% were mildly malnourished, 14.8\% were moderately malnourished and 9.6\% were severely malnourished. This study concluded that most of the children under 5 years' age of Nisdi Rural Municipality, Palpa were malnourished.

Keywords: Under 5 years Children, Malnutrition, Height-for-age, weight-for-age, Waterlow's classification.

\section{INTRODUCTION}

Nutrition, nourishment, or aliment, is the supply of materials - food - required by organisms and cells to stay alive. In science and human medicine, nutrition is the science or practice of consuming and utilizing foods. As molecular biology, biochemistry and genetics advance, nutrition has become more focused on the steps of biochemical sequences through which substances inside us and other living organisms are transformed from one form to another - metabolism and metabolic pathways (Newman, Butler, 2020). Improvement of nutritional status has been seen as some of the most powerful and cost-effective investment for the overall socioeconomic development by enhancing the optimal physical growth and cognitive development especially of women and children (Department of health services, 2013, 2014).

The assessment of the nutritional status involves different techniques which are anthropometry, Biochemical evaluation, clinical examination, and functional assessment, assessment of dietary intake, vital and health statics and ecological studies (Burgess \& Burgess, 1981). Nutrition is the intake of food, considered in relation to the body 's dietary needs. Good nutrition- an adequate, well balanced diet combined with regular physical activity - is a cornerstone of good health. Poor nutrition can lead to reduced immunity, increased susceptibility to disease, impaired physical an $1 \mathrm{~d}$ mental development, and reduced productivity (Shrivastava, shribhastava \& Ramasamy, 2014).

Malnutrition is one of the most important public health problems of developing countries where resources are very limited. Nutrition is believed to be very essential for socio economic development of the country and is an essential component of millennium development goals. The common cause of malnutrition is lack of access to the nutritious food. Poor feeding practices, such as inadequate breastfeeding, offering the wrong foods, and not ensuring that the child gets enough nutritious food, contribute to malnutrition (Chataut \& Khanal, 2016) .

Protein energy malnutrition has been a common health problem of the third world countries Stunting and wasting are common patterns of under-nutrition in children. In children, acute nutritional deficit and/or disease (such as diarrhoea) produce 
wasting, characterized by a reduction in weight-for-height or arm circumference, or both. Prolonged nutritional deficit and/or disease result in stunting, characterized by a reduction in height-for-age. Wasting and stunting are associated with functional consequences. Nutritional assessment involves anthropometric measurement, biochemical tests, clinical observation, functional assessment, dietary survey, ecological study and study of vital statistics (Acharya et al., 2016).

Globally, more than one in four children under the age of five years is too short for their age. Sub-Saharan Africa and South Asia suffer the heaviest burden, with 75\% of the world's stunted children. Low height-for-age or stunting reflects a failure to reach a minimal stature associated with current and future healthy development and is a key indicator of chronic under-nutrition (Goudet, Griffiths, Bogin, \& Madise, 2015).

Globally, PEM continues to be a major health burden in developing countries and the most important risk factor for illnesses and death especially among young children Sub-Saharan Africa bears the brunt of PEM in the world. On the average, the PEM associated mortality in sub- Saharan Africa is between 25 and 35\%. In Nigeria, 22 to $40 \%$ of under-five mortality has been attributed to PEM (Nepal Nutrition Profile, 2014). Nutrition has a dramatic global effect on the mortality and morbidity of children less than five years of age. It is estimated that underlying causes of 35\% deaths of less than five year children. Worldwide over 800 million people are estimated to lack access to food to meet their daily basic needs for energy and protein, while more than 3 billion people are deficient in essential micronutrients like iron, vitamin A and iodine (Ubesi et al., 2012).

Poor children in rural areas, particularly in south Asia, typically exhibit high rate of stunting (short stature for age), while wasting low weight for height) is usually less severe. South-East Asia is the most populated region of the world today. It is the home to over 1.4 billion people or one fourth of the global population. Several nutritional disorders such as beriberi and pellagra have virtually disappeared; remaining disorder of public health concern includes PEM and deficiencies of micronutrients, such as iron, iodine and vitamin A. the conditions which are affecting a large section of the vulnerable groups challenges to health care (UNICEF 2017).

Of the nearly 3 million children under 5 years of age in Nepal, approximately 1.2 million (41\%) are stunted. The NDHS, 2011 has shown 41 percent of children less than 5 years of age suffering from chronic under nutrition (stunting) while more than 10 percent are acutely under-nourished. Additionally, it estimates low birth weight (i.e. very small or smaller than average) 12 per cent. Furthermore, national nutrition status estimates mask wide inequities. The mountain zone has the highest stunting rate of 56 percent, while the Terai has the lowest rate (37.4\%) (Dhungana, 2013).

Malnutrition in children and women is a major public health problem in most of the developing countries and Protein Energy Malnutrition (PEM) is more common among under five year children. Childhood malnutrition is major underlying cause 
$(>50 \%)$ of the under 5 year children deaths. Childhood malnutrition existed in various degrees in different ecological zones and developmental regions of Nepal. Low birth weight, PEM and micronutrient deficiencies were most common form of nutritional problems among under five year children in plain districts of Nepal (Tiwari et al., 2011).

Malnutrition one of the major problems/issues in public health causing/leading to poor nutrition status of the population particularly among young children and is the one of the major problem facing the country. As of the NDHS (2006) about 50 percent of children under five years of age suffer from moderate to severe degree malnutrition.

Malnutrition has both short term and long term effects and lead to higher mortality among children under five years. Due to deficiency of macronutrients and micronutrients many children's increase vulnerable from different communicable diseases. Since, nutritional status of children aged 59 months is a proxy indicator for assessing the entire population health status and one of the major predictors of child survival. Despite the various efforts, malnutrition among children is remaining as a major public health problem in Nepal.

Considering the weight-for-height, height-for-age, BMI-for-age and MUAC-for-age; $5 \%$ to $60 \%$ children were below -2SD (standard deviation) and nearly one-fourth below -3SD. In Kapilvastu more than $60 \%$ children had any kind of malnutrition. Out of them nearly one-fourth children were in critical condition (below -3SD) and they need immediate intervention (Bhandari \& Chhetri, 2013).

A community based Cross-sectional study was conducted to assess the factors associated with nutritional status of under five year children in Rupandehi District of Nepal. Two hundred ninety two children were selected using proportionate random sampling technique. The proportion of the participants was $51.7 \%$ male and $48.7 \%$ female. Nearly half of the children (45.9\%) of the children aged 36-59 months were underweight according to Indian Academy of Pediatrics (NCHS/WHO standard). Fifty percent of the children born to illiterate mothers were found underweight. Majority of the children (65\%) were found stunted according to Waterlow's classification. More than the half the children (57.75\%) were underweight who were born by mother less than 18 years of age where as $75 \%$ were underweight born by mother aged above 35 years of age. However the association between age of the mother at the birth of the child and nutritional status is not statistically significant. More than half of the children were found underweight and Nearly 2/3rd of the children were found stunted. To get better nutritional status of children, greater emphasis should be given to under five years children with community based awareness programs to mother and care givers. 
A study was under taken in Kunchha village development committee to assess nutritional status of children and identify the associated factors. Nutritional status of children age 12-59 month was assessed using anthropometric measurement 9 namely weight, height and mid upper arm circumference (MUAC) using standard procedure. To identify the factor, semi structural questionnaire was used for the mothers. Sixty percent of children had normal nutritional status and $40 \%$ followed by some malnutrition status by Gomez classification. No of ANC visit (odd ratio $=7.54$ and 95\% CI was 1.37 - 41.41), practice during the pregnancy period (P value $<0.021$ ), and feeding practice of extra milk to the children $(\mathrm{P}$ value $<0.037)$ was significantly associated factors (Dhungana, 2013).

A similar cross-sectional study was conducted in Dolakha and Kavre districts of Nepal for assessing the nutritional status of under-five children and associated factors. A total of 243 under five children were included from two purposively selected village development committees (VDCs) i.e. one from each district. Regarding the weight-forheight index, the overall prevalence of wasting in children was 7\%, which was wholly incorporated by moderate acute malnutrition. Severe wasting was null. Strong significant positive correlation was found between weight and height of children $(r=0.81, p<0.01)$. By assessing the height-for-age, $39.9 \%$ of stunting was revealed among which $25.5 \%$ was moderate and $14.4 \%$ was severe. Correlation between height and age of children was found to be significant $(r=0.83, p<0.01)$. According to the results of MUAC, $11.1 \%$ of the under-five children had global acute malnutrition. The moderate acute malnutrition accounted $8.6 \%$ and severe acute malnutrition accounted for $2.5 \%$. Weak positive correlation was found between MUAC measurement and age of children. $(\mathrm{r}=0.26, \mathrm{p}<0.01)$.

By the aforementioned facts of previous published papers our attention was dragged to conduct this study and has focused to find out the status of nutritional status on this rural area by assessing the malnutrition of under five children. This area is also significantly back warded area and most of the population

\section{OBJECTIVES}

The objective of the study was to assess the nutritional status of children of less than 5 years in Magar Community of Nisdi Rural Municipality, Palpa.

\section{METHODOLOGY}

Descriptive and cross sectional study design was used in 2019 to examine the nutritional status of the under 5 years children on the Magar community. The Magar community has basically illiterate background and geographically backward. In this study we applied a validated and used questionnaire set to find out socio-demographic status, to assess height for age (Stunting) of under 5 years' children, weight for height (Wasting) of under 5 years' children, weight for age (Underweight) of under 5 years' children and to measure MUAC of under 5 years' children. We have decided Dependent variables (Underweight, Stunting, Wasting) and 
International Research Journal of MMC (IRJMMC)

Vol. 2

Issue 1 (February, 2021)

ISSN 2717-4999 (Online)

2717-4980 (Print)

Independent Variables on the Demographic variables (Age of the child, Gender of the child, Age of the mother, Number of the children, Religion, Family type, Family size and Ethnicity). Likewise, we have Socio-economic Variables: Education of Mother, Education of Father, Occupation of Mother, Occupation of Father and Family Income). Other Variable were consumption of Colostrum, Exclusive Breastfeeding, Complementary feeding, continued breastfeeding up to 2 years. The study was carried out at Magar Community of Nisdi Rural Municipality, Palpa. The study population was the under 5 years' children from the Magar Community of Nisdi Rural Municipality, Palpa in between 115 children followed by random selection sampling method. Subjects were sampling using sample size from the wards with focusing permanent residents and who were sick children over five years children were excluded. During the study time prior verbal consent was taken. Likewise, the ethical consent was taken from the Nisdi Rural Municipality, Palpa.

\section{RESULT}

A total of 115 respondents were sampled having children aged under five years. The findings of the study are presented in this chapter in the form of tabulation and their interpretation in different headings.

Demographic characteristics of the respondents

Table 1 Demographic distribution of respondents

\begin{tabular}{|l|c|c|}
\hline Characteristics & $\begin{array}{r}\text { Fre } \\
\text { quency } \\
(\mathrm{n}=115)\end{array}$ & ge Percenta \\
\hline $\begin{array}{c}\text { Age of the mother in Years (Mean } \pm \text { SD }: 27.45 \\
\pm 6.054)\end{array}$ & & \\
\hline $15-19$ & 5 & 4.3 \\
\hline $20-24$ & 40 & 34.8 \\
\hline $25-29$ & 32 & 27.8 \\
\hline $30-34$ & 21 & 18.3 \\
\hline $35-39$ & 13 & 11.3 \\
\hline above 40 & 4 & 3.5 \\
\hline Age of the child(Mean \pm SD $: 30.31 \pm 16.629)$ & & \\
\hline less than 6 & 8 & 7.0 \\
\hline $6-11$ months & 6 & 5.2 \\
\hline $12-17$ months & 13 & 11.3 \\
\hline $18-23$ months & 28 & 24.3 \\
\hline $24-30$ months & 4 & 3.5 \\
\hline $31-36$ months & 16 & 13.9 \\
\hline
\end{tabular}


International Research Journal of MMC (IRJMMC)

Vol. 2 Issue 1 (February, 2021)

ISSN 2717-4999 (Online)

2717-4980 (Print)

\begin{tabular}{|l|c|c|}
\hline $37-42$ months & 6 & 5.2 \\
\hline $43-48$ months & 12 & 10.4 \\
\hline $49-54$ months & 11 & 9.6 \\
\hline $55-60$ months & 11 & 9.6 \\
\hline Gender of the child & 69 & 49.3 \\
\hline Male & 71 & 50.7 \\
\hline Female & & \\
\hline No. of children (Mean \pm SD $: 2.56 \pm 1.258)$ & 68 & 59.1 \\
\hline $1-2$ & 37 & 32.2 \\
\hline $3-4$ & 10 & 8.7 \\
\hline above 4 & & \\
\hline Type of Family & 64 & 55.7 \\
\hline Nuclear & 51 & 44.3 \\
\hline Joint & & \\
\hline Family size(Mean \pm SD $: 5.65 \pm 2.164)$ & 47 & 33.6 \\
\hline less than 5 & & \\
\hline
\end{tabular}

\begin{tabular}{|l|l|l|}
\hline Characteristics & Frequency $(\mathrm{n}=115)$ & Percentage \\
\hline $5-8$ & 83 & 59.3 \\
\hline $9-12$ & 10 & 7.1 \\
\hline Religion & & \\
\hline Hinduism & 96 & 83.5 \\
\hline Buddhist & 2 & 1.7 \\
\hline Christianity & 13 & 11.3 \\
\hline Others & 4 & 3.5 \\
\hline Ethnicity & & \\
\hline Brahmin/ Chhetri & 6 & 5.2 \\
\hline Magar & 83 & 72.2 \\
\hline Dalit & 26 & 22.6 \\
\hline
\end{tabular}

The demographic characteristics of the respondents are presented in Table 1. Age wise distribution of the mother showed that majority of the mothers $(34.8 \%)$ were in 20-24 years age group with mean age 27.45 years (SD:6.054). Similarly, $24.3 \%$ of children were in 18-23 months aged group with mean age 30.31 months (SD: 16.629). Out of 115 children, $50.7 \%$ children were female while $49.3 \%$ were male. $59.1 \%$ respondents have 1 or 2 children (Mean \pm SD: $2.56 \pm 1.258$ ). $55.7 \%$ of the total respondents were from nuclear family while $44.3 \%$ were from joint family. The mean family size of the respondents was 5.65 with standard deviation 
International Research Journal of MMC (IRJMMC)

Vol. 2

Issue 1 (February, 2021)

ISSN 2717-4999 (Online)

2717-4980 (Print)

2.164 (Mean \pm SD : $5.65 \pm 2.164$ ). Most of the respondents were Hindu covering $83.5 \%$ followed by Christian covering $11.3 \%$. Majority of the respondents were Magar (72.2\%) followed by Dalit (22.6\%).

Socio-economic characteristics of the respondents

Table 2 Socio-economic distribution of the respondents

\begin{tabular}{|c|c|c|}
\hline Characteristics & Frequency $(n=115)$ & Percent \\
\hline \multicolumn{3}{|l|}{ Mother's educational level } \\
\hline Illiterate & 25 & 21.7 \\
\hline Primary level & 66 & 57.4 \\
\hline Secondary level & 22 & 19.1 \\
\hline Higher secondary level & 2 & 1.7 \\
\hline \multicolumn{3}{|l|}{ Father's educational level } \\
\hline Illiterate & 27 & 23.5 \\
\hline Primary level & 49 & 42.6 \\
\hline Secondary level & 36 & 31.3 \\
\hline Higher secondary level & 3 & 2.6 \\
\hline \multicolumn{3}{|l|}{ occupation of mother } \\
\hline Housewife & 72 & 62.6 \\
\hline Agriculture & $33 \mathrm{a}$ & 28.7 \\
\hline Labour & 4 & 3.5 \\
\hline Business & 5 & 4.3 \\
\hline Others & 1 & 0.9 \\
\hline \multicolumn{3}{|l|}{ Father's occupation } \\
\hline Agriculture & 12 & 10.4 \\
\hline Service & 5 & 4.3 \\
\hline Labour & 66 & 57.4 \\
\hline Business & 10 & 8.7 \\
\hline foreign employment & 7 & 6.1 \\
\hline Others & 15 & 13.0 \\
\hline \multicolumn{3}{|c|}{ monthly income of the family } \\
\hline Low $(<$ Rs 3000) & 2 & 1.7 \\
\hline Medium (Rs 3000-6000) & 1 & .9 \\
\hline High (>Rs 6000) & 112 & 97.4 \\
\hline
\end{tabular}

Table 2 presents the socio-economic characteristics of the respondents. Among 115 respondents, $57.4 \%$ had primary level of education while only $19.1 \%$ had secondary level of education and $21.7 \%$ were illiterate. While $23.5 \%$ of their husbands were illiterate and $42.6 \%$ had primary level of education and $32.3 \%$ had 
International Research Journal of MMC (IRJMMC)

Vol. 2

Issue 1 (February, 2021)

ISSN 2717-4999 (Online)

2717-4980 (Print)

secondary level of education. Most of the respondents were housewife $(62.6 \%)$ followed by agricultural work $(28.7 \%)$. While most of the respondents husbands were labour (57.4\%) followed by agriculture (10.4\%) and business (8.7\%). Almost all respondents had high (>Rs 6000) family monthly income (97.4\%) (Cartmell, Natalal, Francois, Ferreira \& Grahnquist, 2005).

\section{PRACTICE RELATED INFORMATION}

Table 3 Distribution of respondents based on practice

\begin{tabular}{|c|c|c|}
\hline Characteristics & $\begin{array}{r}\mathrm{Fr} \\
\text { equency }\end{array}$ & ntage \\
\hline \multicolumn{3}{|l|}{ Colostrum $(n=115)$} \\
\hline Yes & $\begin{array}{ll} & 11 \\
1 & \end{array}$ & 96.5 \\
\hline No & 4 & 3.5 \\
\hline \multicolumn{3}{|c|}{$\begin{array}{l}\text { Exclusively breastfeeding (months) } \\
(\mathrm{n}=108)\end{array}$} \\
\hline$<6$ months & 31 & 28.7 \\
\hline 6 months & 65 & 60.2 \\
\hline$>6$ months & 12 & 11.1 \\
\hline \multicolumn{3}{|c|}{$\begin{array}{l}\text { Initiation of the complementary feeding } \\
(\mathrm{n}=108)\end{array}$} \\
\hline Below 6 months & 34 & 31.5 \\
\hline 6 months & 61 & 56.5 \\
\hline After 6 months & 13 & 12.0 \\
\hline \multicolumn{3}{|c|}{ Continued breastfed $(n=115)$} \\
\hline Continuing & 69 & 60.0 \\
\hline less than 2 years & 2 & 1.7 \\
\hline more than 2 years & 44 & 38.3 \\
\hline
\end{tabular}

The table 3 showed the distribution related to the practice of breastfeeding. $(96.5 \%)$ children were fed with colostrum. About $60.2 \%$ of the children out of 108 children aged 6-59 months were exclusively breastfed for 6 months. While, $56.5 \%$ children received timely initiation of complementary feeding. Out of 115 children, $60 \%$ were still continuing breastfeeding whereas $1.7 \%$ dropped in less than 2 year and $38.3 \%$ continued for more than 2 years.

Classification of malnutrition based on percentage of the median Table 4 Distribution of respondents by malnutrition classification based on percentage of median 
International Research Journal of MMC (IRJMMC)

Vol. 2

Issue 1 (February, 2021)

ISSN 2717-4999 (Online)

2717-4980 (Print)

\begin{tabular}{|l|c|c|}
\hline & \multicolumn{1}{|c|}{ Frequen } & Perc \\
\hline Percentage of median & $\begin{array}{l}\text { cy } \\
(\mathrm{n}=115)\end{array}$ & \\
\hline Weight for age & & 26.1 \\
\hline $90-110 \%$ (Normal) & 62 & 53.9 \\
\hline $75-89 \%$ (Mildly malnourished) & 19 & 16.5 \\
\hline $60-74 \%$ (Moderately malnourished) & 4 & 3.5 \\
\hline$<60 \%$ (Severely malnourished) & & 46.1 \\
\hline Weight for height & 53 & 40.9 \\
\hline$>90 \%$ (Normal) & 47 & 10.4 \\
\hline $80-89 \%$ (Mildly malnourished) & 12 & 2.6 \\
\hline $70-79 \%$ (Moderately malnourished) & 3 & 52.2 \\
\hline$<70 \%$ (Severely malnourished) & & 23.5 \\
\hline Height for age & 60 & 14.8 \\
\hline$>95 \%$ (normal) & 27 & 9.6 \\
\hline $90-94 \%$ (Mildly malnourished) & 17 & 77.4 \\
\hline $85-89 \%$ (Moderately malnourished) & 11 & 14.8 \\
\hline$<85 \%$ (Severely malnourished) & & 7.8 \\
\hline Mid upper arm circumference (MUAC) & 9 & \\
\hline$>13.5 \mathrm{~cm}$ (satisfactory) & 17 & \\
\hline $12.5-13.5$ cm (mild-moderate malnutrition) & & \\
\hline$<12.5$ cm (severe malnutrition) & & \\
\hline
\end{tabular}

The table 4 Shows the classification of malnutrition for weight for age, weight for height and height for age based on the percentage of the median among 115 under 5 years aged children. Based on Gomez-classification for weight for age (Underweight), only $26.1 \%$ children aged under 59 months were normal (90$110 \%)$. While, more than half (53.9\%) were mildly malnourished (75-89\%), 16.5\% were moderately malnourished $(60-74 \%)$ and $3.5 \%$ were severely malnourished $(<60 \%)$.

Based on Waterlow's classification for Weight for height (wasting), less than half (46.1\%) children aged under 59 months were normal (>90\%). While, 40.9\% were mildly malnourished (80-89\%), 10.4\% were moderately malnourished (70-79\%) and $2.6 \%$ were severely malnourished $(<70 \%)$.

Based on Waterlow's classification for Height for age (Stunting), 52.2\% children aged under 59 months were normal (>95\%). While, 23.5\% were mildly malnourished (90-94\%), 14.8\% were moderately malnourished (85-89\%) and $9.6 \%$ were severely malnourished $(<85 \%)$. 
International Research Journal of MMC (IRJMMC)

Vol. 2

Issue 1 (February, 2021)

ISSN 2717-4999 (Online)

2717-4980 (Print)

Classification of malnutrition based on Z- scores

Table 5 Distribution of respondents by classification of malnutrition based on $\mathrm{Z}$ score

\begin{tabular}{|c|c|c|c|}
\hline Z- score values & $\begin{array}{l}\text { Frequency } \\
(\mathrm{n}=115)\end{array}$ & Percent & ${ }_{\text {alence }}$ Prev \\
\hline $\begin{array}{l}\text { Weight for Age } \\
\text { (WAZ) }\end{array}$ & & & \\
\hline \begin{tabular}{|l}
$-2<\mathrm{Z}$-score $<+2$ \\
(Adequate)
\end{tabular} & 82 & 71.3 & $\begin{array}{ll} & 28.7 \\
& \\
\end{array}$ \\
\hline \begin{tabular}{|l|}
\multicolumn{2}{|c|}{$-3<\mathrm{Z}$-score $<-2$} \\
(Moderately \\
malnourished) \\
\end{tabular} & 21 & 18.3 & \\
\hline $\begin{array}{c}\text { Z-score }<-3 \\
\text { (Severely malnourished) }\end{array}$ & 12 & 10.4 & \\
\hline${ }_{(\mathrm{WHZ})}^{\text {Weight for Height }}$ & & & \\
\hline \begin{tabular}{|l}
$-2<\mathrm{Z}$-score $<+2$ \\
(Adequate)
\end{tabular} & 94 & 81.7 & 18.3 \\
\hline $\begin{array}{l}\quad-3<\text { Z-score }<-2 \\
\text { (Moderately } \\
\text { malnourished) }\end{array}$ & 15 & 13.0 & \\
\hline $\begin{array}{c}\text { Z-score }<-3 \\
\text { (Severely malnourished) }\end{array}$ & 6 & 5.2 & \\
\hline Height for Age(HAZ) & & & \\
\hline $\begin{array}{l}\quad-2<\mathrm{Z} \text {-score }<+2 \\
\text { (Adequate) }\end{array}$ & 81 & 70.4 & 29.6 \\
\hline $\begin{array}{l}\quad-3<\text { Z-score }<-2 \\
\text { (Moderately } \\
\text { malnourished) }\end{array}$ & 16 & 13.9 & \\
\hline $\begin{array}{c}\text { Z-score }<-3 \\
\text { (Severely malnourished) }\end{array}$ & 18 & 15.7 & \\
\hline
\end{tabular}

The table 5 presents the classification of malnutrition for weight for age, weight for height and height for age based on Z-score. For weight for age (WAZ), 71.3\% children aged under 59 months had adequate nutritional status $(-2<\mathrm{Z}$-score $<+2)$, $18.3 \%$ children were moderately malnourished $(-3<Z$-score $<-2)$ and $10.4 \%$ children were severely malnourished (Z-score $<-3)$.

For weight for height (WHZ), 81.7\% children aged under 59 months had adequate 
nutritional status $(-2<\mathrm{Z}$-score $<+2), 13 \%$ children were moderately malnourished $(-3<$ Z-score $<-2)$ and 5.2\% children were severely malnourished (Z-score $<-3)$. Similarly, for height for age (WAZ), 70.4\% children aged under 59 months had adequate nutritional status $(-2<Z$-score $<+2), 13.9 \%$ children were moderately malnourished ($3<Z$-score $<-2$ ) and $15.7 \%$ children were severely malnourished (Z-score $<-3$ ). The table also showed that the prevalence of underweight, stunting and wasting was found to be $28.7 \%, 18.3 \%$ and $29.6 \%$ respectively.

\section{DISCUSSION}

The nutritional assessment was guided by the growth chat of WHO, under five years children on the basis of anthropometric bases were used. Fluctuation of the anthropometric guide from the standard value is consider as proof of starvation. This study analyzed, weight for height, height for age and weight for age as the vital anthropometric indices: called wasting, stunting and underweight respectively. Other than this, mid-upper arm circumference (MUAC) was also measured. For each of these indices, percentage of median was compared based on Gomez classification for weight for age, Waterlow classification for weight for height and height for age (Ferreira, 2020). The result of this study has revealed the existence of high prevalence of malnutrition, especially stunting among under-five children in this study area. Statistically inverse relationship between child's birth weight and stunting is also seen. Taking into account weight, height, age, and MUAC measurements of malnourished children more than three-fifths of them were found below -2SD ( $Z$ score) and nearly one-fourths below 3SD ( $Z$ score) which needs intervention (Tiwari et al., 2014).

A similar study conducted in Rupandehi District of Nepal with two hundred ninety two children in 2008, found that according to Gomez malnutrition classification (NCHS/WHO as standard) for Weight for age, 5.8\% had severe under-nutrition, $33.9 \%$ were moderate under nutrition and $42.5 \%$ were mild under nutrition.

Whereas, the weight for age of under five children of Kolati Bhumlu, we found that $3.5 \%$ were severely malnourished, $16.5 \%$ were moderately malnourished and $53.9 \%$ were mildly malnourished. A similar study conducted with 450 under five children of Kapilvastu district presented that for weight for age (Z-score), 31.5\% children were below the -2 SD and 11.5\% children were below -3 SD (Acharya, Gautam, Kaphle \& Naupane, 2013).

Similarly, a study conducted in Dolakha and Kavre presented that $15.2 \%$ were $-3<-2$ SD and $3.7 \%$ children were below $-3 \mathrm{SD}$ with $18.9 \%$ overall prevalence of underweight 5 . While, in this study, we found $18.3 \%$ children were between $-3<-2$ SD and $10.4 \%$ children were below -3 $\mathrm{SD}$ and the overall prevalence of underweight was found to be $28.7 \%$ which is similar to the NDHS report 2016 of $27 \%$ prevalence rate of underweight. In the same study done in Kapilvastu district, regarding the weight for height index age (Z-score), 16\% children were below the -2 SD and 6\% children were below -3 SD (Bhandari et al., 2013). 
Furthermore, a study conducted in Dolakha and Kavre presented that the overall prevalence of wasting in children was $7 \%$, which was wholly incorporated by $23 \%$ moderate acute malnutrition. While, in this study, we found $13 \%$ children were between $-3<-2$ SD and $5.2 \%$ children were below -3 SD and the overall prevalence of wasting was found to be $18.3 \%$ which is greater than the NDHS report 2016 of 10\% prevalence rate of wasting (Sapkota \& Gurung, 2009).

The study conducted in Rupandehi district, regarding the height for age according to the Waterlow's classification, 5.1\% children were severely malnourished, $14.7 \%$ children were moderately malnourished and $45.2 \%$ children were mildly malnourished. Whereas, the height for age of under five children of Magar community, we found that $9.6 \%$ were severely malnourished, $14.8 \%$ were moderately malnourished and $23.5 \%$ were mildly malnourished. Similarly, another study done in Kapilvastu district, regarding the height for age ( $\mathrm{Z}$ score), $30.8 \%$ children were below the -2 SD and $25 \%$ children were below -3 SD 15 . Also, a study conducted in Dolakha and Kavre presented that 25.5\% children were between $-3<-2$ SD and $14.4 \%$ children were below -3 SD with $39.9 \%$ overall prevalence of stunting. While, in this study, we found $13.9 \%$ children were between $-3<-2$ SD and $15.7 \%$ children were below -3 SD and the overall prevalence of stunting was found to be $29.6 \%$ which is lower than the NDHS report 2016 of $36 \%$ prevalence rate of underweight. Regarding MUAC, the study done in Dolakha and Kavre districts showed that $8.6 \%$ children had moderate acute malnutrition and $2.5 \%$ had severe acute malnutrition. While, in this study we found that $14.8 \%$ children had mildmoderate malnutrition and $7.8 \%$ children had severe malnutrition

\section{CONCLUSIONS}

This study conducted in 115 under 5 children in Magar Community of Nisdi Rural Municipality, Palpa showed that $96.5 \%$ children were fed with colostrum. $60.2 \%$ of the children out of 108 children aged 6-59 months were exclusively breastfed for 6 months. $56.5 \%$ children received timely initiation of complementary feeding. Out of 115 children, $60 \%$ were still continuing breastfeeding whereas $1.7 \%$ dropped in less than 2 year and $38.3 \%$ continued for more than 2 years. According to Gomez-classification for weight for age (Underweight), only $26.1 \%$ children aged under 59 months were normal (90-110\%). While, more than half (53.9\%) were mildly malnourished (75-89\%), 16.5\% were moderately malnourished (60 - $74 \%$ ) and $3.5 \%$ were severely malnourished $(<60 \%)$. Based on Waterlow's-classification for Weight for height (wasting), less than half (46.1\%) children aged under 59 months were normal ( $>90 \%)$. While, $40.9 \%$ were mildly malnourished (80-89\%), 10.4\% were moderately malnourished (70-79 $\%$ ) and $2.6 \%$ were severely malnourished $(<70 \%)$.

Based on Waterlow's-classification for Height for age (Stunting), 52.2\% children aged under 59 months were normal ( $>95 \%$ ). While, 23.5\% were mildly malnourished (90-94\%), $14.8 \%$ were moderately malnourished $(85-89 \%)$ and $9.6 \%$ were severely malnourished $(<85 \%)$. According to the classification of malnutrition based on $\mathrm{Z}$ - score, the prevalence of underweight 
was found to be $28.7 \%$. Similarly, the prevalence of wasting was found to be $18.3 \%$. Also, the prevalence of stunting was found to be $29.6 \%$.

\section{LIMITATIONS}

This cross sectionals study has some limitation on the basis of study design and recall biases. Small size and demography is another limitation. And Cultural, daily consuming food and education can be significantly associated to have malnutrition in this study population area. Thus, it cannot be generalized as a whole however, it can share a significant situation of children to the local level administrative or policy level.

Conflicts of Interest: The authors declare no conflict of interest.

\section{ACKNOWLEDGMENTS}

To those who were given consent to participate in this study.

Author Contributions: We three conceived and developed this study and drafted the manuscript. Gaire collected the data and Pathak and Raikhola was set to design the study and whole formatting and editing helped ethical writing and supervised. All authors PSR, TG and KPP managed the manuscript.

\section{CONFLICT OF INTEREST}

The authors declare no conflict of interest.

\section{REFERENCES}

Acharya, D., Gautam, S., Kaphle, H. P., \& Naupane, N. (2013). Factors associated with nutritional status of under five children in Rupandehi District of Nepal. Journal of Health and Allied Sciences, 3(1), 56-59.

Department of health services, Annual Report. (2013 \& 2014). https://dohs.gov.np/wpcontent/uploads/2014/04/Annual_Report_2070_71.pdf.

Medical News Today (2017). What is nutrition, and why does it matter? https://www.medicalnewstoday.com/articles/160774.

Burgess, H.J.L., \& Burgess, A.P. (1981). Community nutrition. In: Wallace H.M., Ebrahim G.J. (eds) Maternal and Child Health Around the World. Palgrave, London. doi.org/10.1007/978-1-349-05386-5_39.

Shrivastava, S.R.B., shribhastava, P.A., \& Ramasamy, J. (2014). Assessments of nutritional status in the community and clinical settings. Journal of medical science,35(5) 211.-213. doi: 10.4103/1011-4564.143648.

Chataut, J., \& Khanal, K. (2016). Assessment of nutritional status of children under five years of age in rural Nepal. Kathmandu University of Medical Journal,53(1):73-7.

Bhattacharya, A., Pal, B., Mukherjee, S., \& Roy, S.K. (2019). Assessment of nutritional status using anthropometric variables by multivariate analysis. BMC Public Health, 19: 1045, Aug 5. doi: 10.1186/s12889-019-7372-2. 
Goudet, S.M., Griffiths, P.L., Bogin, B.A., \& Madise, N.J. (2015). Nutritional interventions for preventing stunting in children (0 to 5 years) living in urban slums. Cochrane Database Systematic Reveview, (5): CD011695. doi: 10.1002/14651858.CD011695.

Nepal Nutrition Profile (2014). Food and Nutrition Technical Assistance III Project. 2014 Associated in Kapilvastu District, Nepal. Journal of nutritional health and food science; 1(1): 6 .

Ubesie, A. C., Ibeziako, N. S., Ndiokwelu, C. I., Uzoka, C. M., \& Nwafor, C. A. (2012). Underfive protein energy malnutrition admitted at the University of in Nigeria teaching hospital, Enugu: a 10 year retrospective review. Nutrition journal, 11(1), 1-7.

UNICEF, (2016). The faces of malnutrition. Available from (http://www.unicef.org/nutrition/) Accessed at 21thJanuary,2017.

WHO, (2016). Nutrient profile model for South-East Asia Region. https://apps.who.int/iris/handle/10665/253459.

Dhungana, GP. (2013). Nutritional status of under 5 children and associated factors of Kunchha village development committee. Journal of Chitwan Medical College, 3(6): 38-42.

Tiwari, R., Ausman, L. M., \& Agho, K. E. (2014). Determinants of stunting and severe stunting among under-fives: evidence from the 2011 Nepal Demographic and Health Survey. BMC pediatrics, 14(1), 1-15. https://doi.org/10.1186/1471-2431-14-239.

Bhandari, T.R. \& Chhetri, M. (2013). Nutritional status of under five year children and factors associated in Kapilvastu District, Nepal. Journal of Nutrition Health and Food Science, 1 (1): 6. http://dx.doi.org/10.15226/jnhfs.2013.00106.

Cartmell, E., Natalal, H., Francois, I., Ferreira, M.H., Grahnquist, L. (2005). Clinical Status of Children Admitted to the Malnutrition Ward, Maputo, Central Hospital: A Comparison of Data from 2001 and 1983. Journal of Tropical Pediatrics,.51(2):102-5. Epub 2005 Jan 26.doi: $10.1093 / \mathrm{tropej} / \mathrm{fmh} 088$.

Sapkota, V.P., \& Gurung, C.K. (2009). Prevalence and Predictors of Underweight, Stunting and Wasting in Under-Five Children. Journal of Nepal Health Research Council, 7(15):12026.doi: 10.1093/tropej/50.5.260.

Ferreira, H.D.S. (2020). Anthropometric assessment of children's nutritional status: a new approach based on an adaptation of Waterlow's classification. BMC Pediatrics, 20, 65). https://doi.org/10.1186/s12887-020-1940-6. 